\title{
A multicenter controlled study for dementia prevention through physical, cognitive and social activities - GESTALT-kompakt
}

This article was published in the following Dove Press journal:

Clinical Interventions in Aging

\begin{abstract}
Anna Streber
Karim Abu-Omar

Christian Hentschke

Alfred Rütten

Department of Sport Science and Sport, Faculty of Humanities, Social Sciences, and Theology, FriedrichAlexander-University of ErlangenNürnberg, Erlangen, Germany
\end{abstract}

\begin{abstract}
Prevention of dementia is a public health priority. Physical activity (PA) can reduce the risk of dementia, but the majority of people remain sedentary. We conducted a multicenter controlled study with older adults (60+ years). We hypothesized that an evidence-based PA intervention - GEhen, Spielen und Tanzen Als Lebenslange Tätigkeiten - kompakt [walking, playing and dancing as lifelong activities-compact] (GESTALT-kompakt) - would lead to significantly larger improvements in PA levels (step counts/Fitbit Zip ${ }^{\mathrm{TM}}$ ), cognitive functions (DemTect) and social activities (Social Activity Log), compared to an active control group. Data were collected at baseline and after 3 and 12 months. The intervention group received a 12-week (1/week) multimodal and multicomponent PA program, which combined PA with cognitive and social activities. The control group received either regular gymnastics or cognitive training (1/week). A mixed linear model was chosen for analysis. A total of 87 older individuals were recruited in the GESTALT-kompakt study ( 68 females, average age $=76.0$ years, $\mathrm{SD} \pm 9.2$, range 52-95 years). Marginally significant differences were observed in the intervention group $(n=57)$ in comparison to the control group $(n=30)$, regarding improvements in PA (difference of mean changes $=866.4$ steps, $p=0.055$ ) after 3 months. However, their PA decreased to the baseline score value after 12 months $(-866.0$ steps, $p=0.061)$. GESTALT-kompakt did not cause significant differences in cognitive functioning $(-0.8620, p=0.074)$ and social activities $(-0.2428, p=0.288)$ in comparison to the control intervention from T0 to T1. Sixteen $(24.2 \%)$ study participants who finished $\mathrm{T} 2$ reported a negative life event during the follow-up period, which severely influenced their PA behavior. GESTALT-kompakt might be effective in increasing PA in the short term, but did not have a long-term impact on the PA levels, cognitive functions or social activities of the participants. We recommend PA programs with longer duration to change behavior in the long term.
\end{abstract}

Keywords: aging, intervention, physical activity program, cognitive function, social activity, dementia

\section{Background}

Dementia has become a global health problem, and it is increasingly recognized as being a high public health priority. ${ }^{1}$ G8 member state meetings in 2013 and the Dementia Summit in $2014^{2}$ concluded that the prevention of dementia should become the main focus in public health policies and actions to counteract the dementia epidemic. Recent studies have shown the importance of tackling the impairment of cognitive abilities in dementia with neuropsychologic interventions. ${ }^{3-5}$ But Wu et al give the policy implication that it is primary prevention that has the largest effect on reduction of occurrence of later dementia and disability. ${ }^{6}$ 
The promotion of a healthy lifestyle, including being a nonsmoker, having a body mass index between 18 and 25, high fruit and vegetable intake, regular physical activity (PA) and low/moderate alcohol intake, is one of the key strategies to reduce the incidence of dementia. The Caerphilly Cohort study, which followed over 2,000 males over 30 years, showed that a healthy lifestyle, based on four out of five healthy behaviors, can reduce the incidence of dementia by $60 \%{ }^{7}$ Especially, the promotion of PA and, in particular, regular physical exercise training may have the potential to reduce the risk of dementia onset. On the one hand, research results indicate that ongoing, lifelong, moderate-intensity physical exercise behavior and varying leisure time activities have the potential to prevent the risk of dementia. ${ }^{89}$ On the other hand, a systematic review and expert consensus identified physical inactivity as an important risk factor and potentially modifiable prevention target next to other modifiable risk factors such as depression, (midlife) hypertension, diabetes, (midlife) obesity, hyperlipidemia and smoking behavior. ${ }^{10}$ Nonmodifiable risk factors for dementia are age, genetic disposition and gender. ${ }^{11}$

The mechanisms by which PA affects the onset of dementia are complex and multifactorial. PA tackles comorbidities such as cardiovascular diseases, depression and type II diabetes, ${ }^{12-16}$ which are known to contribute to vascular and neurodegenerative dementia. ${ }^{17}$ Regarding cognitive functions, PA interventions have been developed and tested in controlled trials that demonstrate positive effects on cognitive functioning in older people, ${ }^{8,18-20}$ even though there is conflicting evidence. ${ }^{21}$ Recent evidence has shown that the combination of cognitive and physical training might be more effective for preventing dementia than the training of just one of both..$^{22,23}$ The combination of PA with cognitive challenges might be particularly effective in inducing beneficial prevailing effects on the brain structure and function, due to the facilitating effects on learning through PA (eg, angiogenesis, availability of certain neurotrophins) and the neuronal changes induced through cognitive training. ${ }^{24}$ To enhance cognitive performance and overall function in older adults, evidence supports structured, multicomponent exercise programs with long durations. ${ }^{25}$ Besides a physically active lifestyle, a socially integrated lifestyle in late life may also have the potential to prevent dementia. ${ }^{26}$ In the field of social relationships, low social participation, more loneliness and less frequent social contact were statistically significantly associated with incident dementia. ${ }^{27}$ Thus, the best strategy to reduce the risk of cognitive impairment might be interventions that include cognitive, social and physical components. ${ }^{24,28}$
Despite increasing evidence for the protective effects of PA on the development of dementia, the majority of people remain sedentary. Data from the Eurobarometer indicate that across Europe, only 10\% of respondents aged 55-69 and only $8 \%$ of respondents aged 70 years and older engage in regular PA. ${ }^{29}$

A major challenge is the development and implementation of effective dementia prevention programs for the health care system. In Germany, standard prevention protocol lacks specific PA programs for dementia prevention, based on the latest evidence (eg, multimodal including physical, social and cognitive activities). Standard prevention programs comprise short-term courses that last a maximum of 12 weeks $(1 \times /$ week $)$ and only address single mechanisms as outlined earlier.

In this regard, we developed the GESTALT (GEhen, Spielen und Tanzen Als Lebenslange Tätigkeiten [walking, playing and dancing as lifelong activities]) intervention, which is an evidence-based, multimodal PA program that combines PA with cognitive and social activities and comprises behavior change techniques to empower participants to initiate and maintain regular physical, cognitive and social activities in the long term.

\section{GESTALT}

The multimodal PA intervention GESTALT ${ }^{30,31}$ comprises the latest evidence for dementia prevention through systematically integrating cognitive training (eg, memory training, step sequences) and social/emotional interaction (eg, conviviality, body contact) into a PA program (eg, endurance, strength, postural balance). This group-based program has been designed to target the sedentary lifestyle of older adults and to engage them in the World Health Organization's recommended 150 min of moderate-intensity PA per week ${ }^{32}$ as well as in types of exercises that are known to be especially effective, such as dancing. ${ }^{33}$

To fit the existing conditions for federal subsidies for prevention programs in Germany, the original GESTALT program was adapted. ${ }^{30,31}$ Preserving the core elements and foundations of GESTALT, we developed a 12-week version of the original program - GESTALT-kompakt [compact]to be suitable for financial support from German health insurances $(80 \%$ of the participant fee is refundable [twice a year] by German health insurances if the participant was joining the primary prevention program on a regular basis; for this, the program has to meet several requirements) and, therefore, to be sustainably implemented in real-world prevention practice. 
The major aim of this study was to analyze the shortand long-term effectiveness of the GESTALT-kompakt program compared to the standard prevention approach in Germany in real-world settings. We hypothesized that in older adults, the program GESTALT-kompakt would result in a significantly higher increase in PA (primary outcome) until the end of the intervention ( 3 months) and until the follow-up after 12 months, in comparison to the control group. We further hypothesized that GESTALT-kompakt would lead to significantly larger improvements in cognitive functions and social activities (secondary outcomes), compared to the control group.

\section{Subjects and methods Study design and procedures}

The GESTALT-kompakt study is an effectiveness study in between the endpoints of being pragmatic and explanatory. ${ }^{34}$ Accordingly, the Pragmatic-Explanatory Continuum Indicator Summary and Pragmatic-Explanatory Continuum Indicator Summary 2 were used for study design (Table 1).35,36
The emphasis on measuring effects in real-world settings was chosen because of its importance for sustaining the intervention in practice to create a public health impact. In this regard, implementation and evaluation were framed in a participatory process involving all relevant stakeholders. ${ }^{37}$

The GESTALT-kompakt study is a multicenter controlled study for dementia prevention, tackling multiple risk factors through a multicomponent intervention. Overall, five intervention and three control groups were involved in two settings (community-based and assisted living). Due to practicability reasons in the settings, no randomization or blinding of either participants or evaluators was conducted. Participants gave written informed consent at baseline.

\section{Target group and recruitment}

The target group consisted of individuals $(60+$ years $)$ at risk for dementia with one or more modifiable risk factors (see the "Background" section) which were assessed at baseline. As usual in prevention practice, there were no explicit inclusion

Table I Classification of GESTALT-kompakt on the PRECIS $2^{36}$ continuum

\begin{tabular}{|c|c|c|}
\hline PRECIS 2 domains & Score & Rationale \\
\hline Eligibility criteria & 5 & $\begin{array}{l}\text { All people who responded to recruitment were allowed to participate in the study (no exclusion } \\
\text { criteria). The reference value for age was } 60 \text { years and older, but persons were not excluded if } \\
\text { they were younger }\end{array}$ \\
\hline Recruitment path & 4 & $\begin{array}{l}\text { Usual paths of prevention providers were used to recruit participants. But providers were } \\
\text { supported by the project coordinator providing materials and contents }\end{array}$ \\
\hline Setting & 5 & $\begin{array}{l}\text { Identical settings to usual prevention care were chosen as the intervention was taking place in the } \\
\text { venues of five prevention providers (two in the setting of assisted living and three in a community } \\
\text { setting). Equal for control groups }\end{array}$ \\
\hline Organization intervention & 4 & $\begin{array}{l}\text { Identical organizations to usual practice were chosen. Organizations did not require more } \\
\text { than usual experience and no increase of resources. Physical activity trainers (provided by the } \\
\text { organizations themselves) had to join an additional training before implementing GESTALT- } \\
\text { kompakt }\end{array}$ \\
\hline $\begin{array}{l}\text { Flexibility of experimental } \\
\text { intervention - delivery }\end{array}$ & 2 & $\begin{array}{l}\text { Trainers had to follow a strict protocol (trainer manual) regarding the content of the intervention } \\
\text { and fill in a short feedback protocol for each session for the head of project. Only small adaptions } \\
\text { of contents regarding the health status and physical activity levels of participants in the different } \\
\text { settings were allowed }\end{array}$ \\
\hline $\begin{array}{l}\text { Flexibility of experimental } \\
\text { intervention - adherence }\end{array}$ & 4 & $\begin{array}{l}\text { There was no more than usual encouragement to adhere to the intervention Participants who } \\
\text { missed class more than once were called and asked for the reason Trainers were keeping } \\
\text { an attendance list to document how many sessions ( } \max 12 \text { ) the participants were joining. } \\
\text { Participants were not excluded if they were not adherent }\end{array}$ \\
\hline Follow-up & I & $\begin{array}{l}\text { Participants were passing three measurements (pre/post/follow-up) of their physical, cognitive } \\
\text { and social activities during the study. Participants were having two additional, scheduled follow-up } \\
\text { visits by the researchers, particularly for intervention-related data collection. In usual practice, no } \\
\text { follow-up visits are carried out }\end{array}$ \\
\hline Outcome & 5 & $\begin{array}{l}\text { Primary outcome - increase of physical activity - was commonly chosen by prevention providers } \\
\text { and scientists and is easy for the participants to comprehend }\end{array}$ \\
\hline Analysis & 5 & All available data were used for analysis \\
\hline Mean value & 3.89 & \\
\hline
\end{tabular}

Note: Likert scale I-5 (I= very explanatory, $2=$ rather explanatory, $3=$ equally, $4=$ rather pragmatic, $5=$ very pragmatic).

Abbreviations: GESTALT, GEhen, Spielen und Tanzen Als Lebenslange Tätigkeiten [walking, playing and dancing as lifelong activities]; PRECIS, pragmatic-explanatory continuum indicator summary. 
or exclusion criteria. The target group was recruited from the general population and the assisted living facilities.

Prevention providers recruited participants for the intervention group from November 2014 until February 2015. Applied strategies were: flyer ( $5 / 5$ providers $)$, placards $(5 / 5)$, information event (4/5), local newspaper article (3/5), promotion video $(3 / 5)$, advertisement in program booklet of provider (2/5) and letter to residents in assisted living (1/5). Providers were supported by the project coordinator who provided the listed material and contents. To ensure the recruitment of target group participants, the material emphasized a present lower level of PA. The control group interventions were regular offers provided in real-world prevention practice. Participants for the control groups were, therefore, independently recruited through established strategies of providers, such as entry in the program booklet and word-of-mouth advertising.

\section{Intervention and providers}

GESTALT-kompakt as well as the control interventions were carried out by five prevention providers in Bavaria, Germany. Three of them worked in the community-based setting (sports club, protestant education institute, local sports department - providers 1-3) and two providers were from assisted living facilities (providers 4 and 5). Providers were selected by the project coordinatior to ensure a mix of settings and organizations. Instructors were eligible if they were employed by the provider, qualified exercise instructors and interested in the program. A description of qualification, age, gender and professional experience of instructors for the intervention and control groups is provided in Table 2.

\section{Intervention group}

The GESTALT-kompakt intervention is a multimodal PA program with 12 sessions. Each session lasts 90 min once a week and includes two accompanying modules. Module 1 is an evidence-based multimodal PA program integrating social and cognitive activities (60 min). Module 2 is a PA coaching program (30 min).

Module 1 contains PA in daily routines and walking (eg, walking through activity trails), sports and games (eg, playing with balloons and balls) and dance and movement to music (eg, line and square dance). Different materials, contents and didactic methods are used to create various demands, mainly for the endurance and coordination of participants. Module 2 aims to enable participants to transfer and maintain the recommended PA level into their daily lives. The main contents are mood and barrier management, rewarding strategies, goal setting and knowledge transfer and address PA preferences of participants. Table 3 shows the outline of GESTALT-kompakt with its structure and main contents.

The program is divided into four stages. During the first 3 weeks (stage 1), participants get to know the program, the teacher and each other, and gather first experiences in movement. From here on, the weekly instructed sessions are complemented with additional tasks and experiences for participants to foster the aims of the intervention: During stage 2 (weeks 4-6), participants receive tasks to practice at home. During stage 3 (weeks 7-9), the whole group additionally takes part in three excursions with their instructor in the near surrounding, in order for the participants to get to know further PA offers. Stage 4 (weeks 10-12) participants additionally have three excursions in smaller groups without their instructor.

Table 2 Description of the instructors of GESTALT-kompakt and control groups

\begin{tabular}{|c|c|c|c|c|c|c|}
\hline & Provider I & Provider 2 & Provider 3 & Provid & 4 & Provider 5 \\
\hline Group & CG and IG & CG and IG & IG & IG & CG & IG \\
\hline Gender & $\mathrm{F}$ & $\mathrm{F}$ & $\mathrm{F}$ & $\mathrm{F}$ & $\mathrm{F}$ & M \\
\hline Age (years) & 49 & 58 & 46 & 47 & 66 & 46 \\
\hline $\begin{array}{l}\text { Years of professional experience as } \\
\text { physical education teacher }\end{array}$ & 25 & 35 & 7 & 13 & 8 & 4 \\
\hline Years of experience working with elderly & 25 & 35 & 6 & 12 & 8 & 17 \\
\hline Qualification & $\begin{array}{l}\text { State-certified physical } \\
\text { education teacher }\end{array}$ & $\begin{array}{l}\text { Licensed } \\
\text { by BLSV }\end{array}$ & $\begin{array}{l}\text { Dipl. Pedagogue (sports } \\
\text { and psychology) }\end{array}$ & $\begin{array}{l}\text { Licensed } \\
\text { by BLSV }\end{array}$ & $\begin{array}{l}\text { Licensed } \\
\text { by BVGT }\end{array}$ & $\begin{array}{l}\text { Licensed } \\
\text { by BLSV }\end{array}$ \\
\hline Previous experience with GESTALT & None & None & None & $\begin{array}{l}\text { Trainer of a } \\
\text { previous group }\end{array}$ & None & None \\
\hline $\begin{array}{l}\text { Employment relationship in } \\
\text { GESTALT-kompakt }\end{array}$ & Freelancer & Freelancer & Freelancer & Freelancer & Freelancer & Freelancer \\
\hline General employment & Freelancer & Freelancer & $\begin{array}{l}\text { Office worker } \\
\text { (part time) }\end{array}$ & $\begin{array}{l}\text { Office worker } \\
\text { (part time) }\end{array}$ & Retired & $\begin{array}{l}\text { Geriatric } \\
\text { nurse }\end{array}$ \\
\hline
\end{tabular}

Abbreviations: BLSV, Bayerischer Landes-Sportverband eV; BVGT, Bundesverband Gedächtnistraining eV; CG, control group; GESTALT, GEhen, Spielen und Tanzen Als Lebenslange Tätigkeiten [walking, playing and dancing as lifelong activities]; IG, intervention group; f, female; m, male. 
Table 3 Outline of the GESTALT-kompakt intervention

\begin{tabular}{|c|c|c|c|c|}
\hline \multirow[t]{2}{*}{ Session } & \multirow[t]{2}{*}{ Stage } & \multicolumn{2}{|l|}{ Module I } & \multirow{2}{*}{$\begin{array}{l}\text { Module } 2 \text { coaching } \\
\text { and theory }\end{array}$} \\
\hline & & Topic of PA session & Main PA content & \\
\hline 1 & \multirow{3}{*}{$\begin{array}{l}\text { Stage I: To get to } \\
\text { know each other and } \\
\text { gain first experiences } \\
\text { of movement }\end{array}$} & $\begin{array}{l}\text { Get to know each other } \\
\text { through movement and play }\end{array}$ & $\begin{array}{l}\text { Games with } \\
\text { balloon }\end{array}$ & $\begin{array}{l}\text { Goals of intervention and } \\
\text { dementia prevention }\end{array}$ \\
\hline 2 & & $\begin{array}{l}\text { Gather experience with } \\
\text { different materials to music }\end{array}$ & Square dance & $\begin{array}{l}\text { Advantages of PA for } \\
\text { prevention and Borg-scale }\end{array}$ \\
\hline 3 & & $\begin{array}{l}\text { Gather experience with } \\
\text { materials in an activity trail }\end{array}$ & Activity trail & $\begin{array}{l}\text { Motives for participation in } \\
\text { course and PA }\end{array}$ \\
\hline 4 & \multirow{3}{*}{$\begin{array}{l}\text { Stage 2: Preparation } \\
\text { of the transfer into } \\
\text { everyday life }\end{array}$} & $\begin{array}{l}\text { Play together - Part I+ } \\
\text { impulse for activities at home }\end{array}$ & $\begin{array}{l}\text { Games with } \\
\text { balloon }\end{array}$ & Goal setting I \\
\hline 5 & & $\begin{array}{l}\text { Move together - Part I + } \\
\text { impulse for activities at home }\end{array}$ & $\begin{array}{l}\text { Endurance and } \\
\text { coordination }\end{array}$ & $\begin{array}{l}\text { Goal setting II and function } \\
\text { of the memory }\end{array}$ \\
\hline 6 & & $\begin{array}{l}\text { Walk together - Part I + } \\
\text { impulse for activities at home }\end{array}$ & $\begin{array}{l}\text { Walking with } \\
\text { memory tasks }\end{array}$ & $\begin{array}{l}\text { Mood and barrier } \\
\text { management }\end{array}$ \\
\hline 7 & \multirow[t]{3}{*}{$\begin{array}{l}\text { Stage 3: Transfer into } \\
\text { everyday life }\end{array}$} & $\begin{array}{l}\text { Play together - Part II + } \\
\text { excursion with instructor }\end{array}$ & $\begin{array}{l}\text { Games with } \\
\text { parachute }\end{array}$ & Barrier plan I \\
\hline 8 & & $\begin{array}{l}\text { Move together - Part II + } \\
\text { excursion with instructor }\end{array}$ & Line dance & $\begin{array}{l}\text { Barrier plan II and } \\
\text { rewarding strategies }\end{array}$ \\
\hline 9 & & $\begin{array}{l}\text { Walk together - Part II + } \\
\text { excursion with instructor }\end{array}$ & Walking symbols & Added value of being active \\
\hline 10 & \multirow[t]{3}{*}{$\begin{array}{l}\text { Stage 4: Sustainability } \\
\text { and self-determination }\end{array}$} & $\begin{array}{l}\text { Play together - Part III + } \\
\text { independent excursion }\end{array}$ & $\begin{array}{l}\text { Games with balls, } \\
\text { wooden staff and towels }\end{array}$ & $\begin{array}{l}\text { Information about offers } \\
\text { and suitable types of activity }\end{array}$ \\
\hline 11 & & $\begin{array}{l}\text { Move together - Part III + } \\
\text { independent excursion }\end{array}$ & $\begin{array}{l}\text { Endurance and } \\
\text { coordination }\end{array}$ & Social support \\
\hline 12 & & $\begin{array}{l}\text { Walk together - Part III + } \\
\text { independent excursion }\end{array}$ & $\begin{array}{l}\text { Walking with } \\
\text { different materials }\end{array}$ & $\begin{array}{l}\text { Reflection of the course } \\
\text { and changes in PA behavior }\end{array}$ \\
\hline
\end{tabular}

Notes: Main focus: red = playing; green = dancing; blue = walking.

Abbreviations: GESTALT, GEhen, Spielen und Tanzen Als Lebenslange Tätigkeiten [walking, playing and dancing as lifelong activities]; PA, physical activity.

To implement GESTALT-kompakt, qualified PA instructors were trained in a 2-day seminar by the principal investigator. They were given a written instructors manual containing an extensive description of each PA session (goals, didactics, content, timeline, materials and essentials) including instructions for the PA coaching.

\section{Control group}

Three independent groups - one memory training and two PA groups - served as control groups. All sessions were group based, took place once a week and lasted 45-60 min. Main contents of memory training were brainteasers and riddles while sitting. One PA group did movements during sitting and standing, while the other did moderate-intensity gymnastics and strength training with small equipment. In all sessions, there was no simultaneous performance of physical and cognitive tasks. The intervention group instructors also carried out the control group sessions.

\section{Ethical approval}

Ethical approval for research within GESTALT was granted by the Bavarian Health and Food Safety Authority, the project agency of the Bavarian State Ministry of the environment and public health.

\section{Outcome measures}

All assessments were undertaken at the beginning (T0), at the end (T1) and 12 months after the beginning of the intervention (T2), respectively.

\section{Physical activity}

To measure the PA levels, the participants wore a waistmounted pedometer (Fitbit Zip ${ }^{\mathrm{TM}}$ [advantages \{especially for older adults $\}$ : no charging, no turning off and on, no reading and note down of steps required, relatively low costs, 7-day memory, high practicability]) during waking hours for 7 consecutive days at all three points of measurement. The Fitbit Zip has proven to be a valid activity monitor to measure PA. ${ }^{38}$ Participants were asked to continue with their typical activities and to remove the pedometer only while bathing, showering or swimming. Simultaneously, participants kept a PA diary and noted any incidence of, for example, illness. At T2, a written form was added to the diary, which asked the participants to report any negative life events (eg, falls, fractures and surgeries) since $\mathrm{T} 1$ that influenced their PA behavior. The diary was pretested in a small group of older adults $(n=10)$ to learn about its usability and meaningfulness for this target group. Minor changes were made regarding the font size, and valuable 
information was gathered regarding handling and difficulties filling in the diary.

For analysis, the pedometer data (day-end steps taken) were summed and divided by the number of days it was worn to compute the mean steps per day. To be representative, all days were screened if the pedometer had been worn at least $8 \mathrm{~h}$ per day without major gaps $(>6 \mathrm{~h}$ ). Missing days (unrecorded data) or unrepresentative days (illness and holidays) were excluded. Participants had to have at least 3 valid days out of 7 days of measurement. No distinction was made between workdays and weekends. To interpret the PA levels, the mean steps were assigned to the categories of the graduated step index (steps/day: $<2,500=$ basal activity; 2,500-4,999= limited activity; 5,000-7,499= low activity; 7,500-9,999= somewhat active; $10,000-12,499=$ active; $\geq 12,500=$ highly active) of Tudor-Locke et al. ${ }^{39}$ Participants rated their satisfaction with the program on a five-point Likert scale at the end of the intervention.

\section{Cognitive functions}

The DemTect was used to measure cognitive functioning. It is valuable for detecting and differentiating cognitive dysfunction when symptoms begin. ${ }^{40}$ It contains five subtests: word list (short-term verbal memory), transcoding of numbers (executive function), supermarket task (word fluency), digit span reverse (short-term and working memory) and delayed recall of wordlist (long-term verbal memory). Results are transformed via a scoring routine and summed up to a total score (0-18 points). For interpretation, high values indicate good cognitive functioning. With a cutoff of 13 points (for mild cognitive impairment), the DemTect has a high sensitivity (97.6\%) and specificity (92.9\%) to detect possible cognitive impairment. ${ }^{41}$ A good retest reliability was shown. ${ }^{42}$ To reduce recall bias, two available versions of the test were used alternately.

\section{Social activity}

The concept of social health is multifaceted and hard to measure. ${ }^{43}$ As GESTALT-kompakt participants were partly free living and partly in assisted living, the instrument had to mirror both living conditions.

The "Social Activity Log" questionnaire was designed to capture the frequency and diversity of social activities outside of daily responsibilities. ${ }^{44}$ As there was no German version available, the questionnaire was translated into German (process: translation by a native German speaker; retranslation by a native English speaker; final corrections by scientific board). The scoring manual was provided by the original authors. The Social Activity Log comprises 13 items and three subscales, which categorize activities into "low contact", "moderate contact", and "contact per mail or phone". It provides subscale mean scores and a total mean score (0-6 points). Higher values indicate more social activity.

\section{Statistical analysis}

For statistical analysis of the primary and secondary outcomes, a mixed linear model was chosen, which is particularly suitable for the analysis of longitudinal data resulting from the time-repeated observation of individuals in the context of longitudinal studies. The mixed linear model used is based on a $3 \times 2$ factorial design with three time points and two groups (intervention vs control). Time effects from baseline to the first and from the first to the second measurement time point, group effects and interactions between time and group were considered as fixed effects and intercept and slope were considered as random effects in the model. Here, the linear change from $\mathrm{T} 0$ to $\mathrm{T} 1$ is relevant for the effect within the intervention phase. The linear change from T1 to T2 is relevant for the effect in the follow-up phase. In addition, differences in the overall effect of the intervention over both phases were tested. For this purpose, the given statistical model (hypothesis model), containing the main effects and the interaction effects of the two phases of the factor "time" by the factor "group", was compared to a model (zero model) that only contained the main effects of the above-mentioned factors in a likelihood ratio test. The primary analysis was not adjusted for other covariates.

Missing values were not replaced. However, the mixed linear model does enclose all available information into the analysis. Results are, therefore, undistorted under a missing at random assumption.

\section{Results}

\section{Sample characteristics}

Eighty-seven people joined the study. Fifty-seven pertained to the intervention group and 30 to the control group. Dropout reasons are shown in the participant flow diagram (Figure 1). Three participants were excluded from the analysis because of prevalent dementia at baseline.

Baseline characteristics (Table 4) differed regarding the PA levels (mean steps/day were lower in the control group as in the intervention group). Control group participants were more prone to using a walking aid, having heart complaints, suffering from mild cognitive impairment, having a pulmonary disease and suffering from allergies. GESTALT-kompakt participants were more prone to suffering from depression and living alone. Further, our group of participants represents the Bavarian population for this age group. ${ }^{45,46}$ 


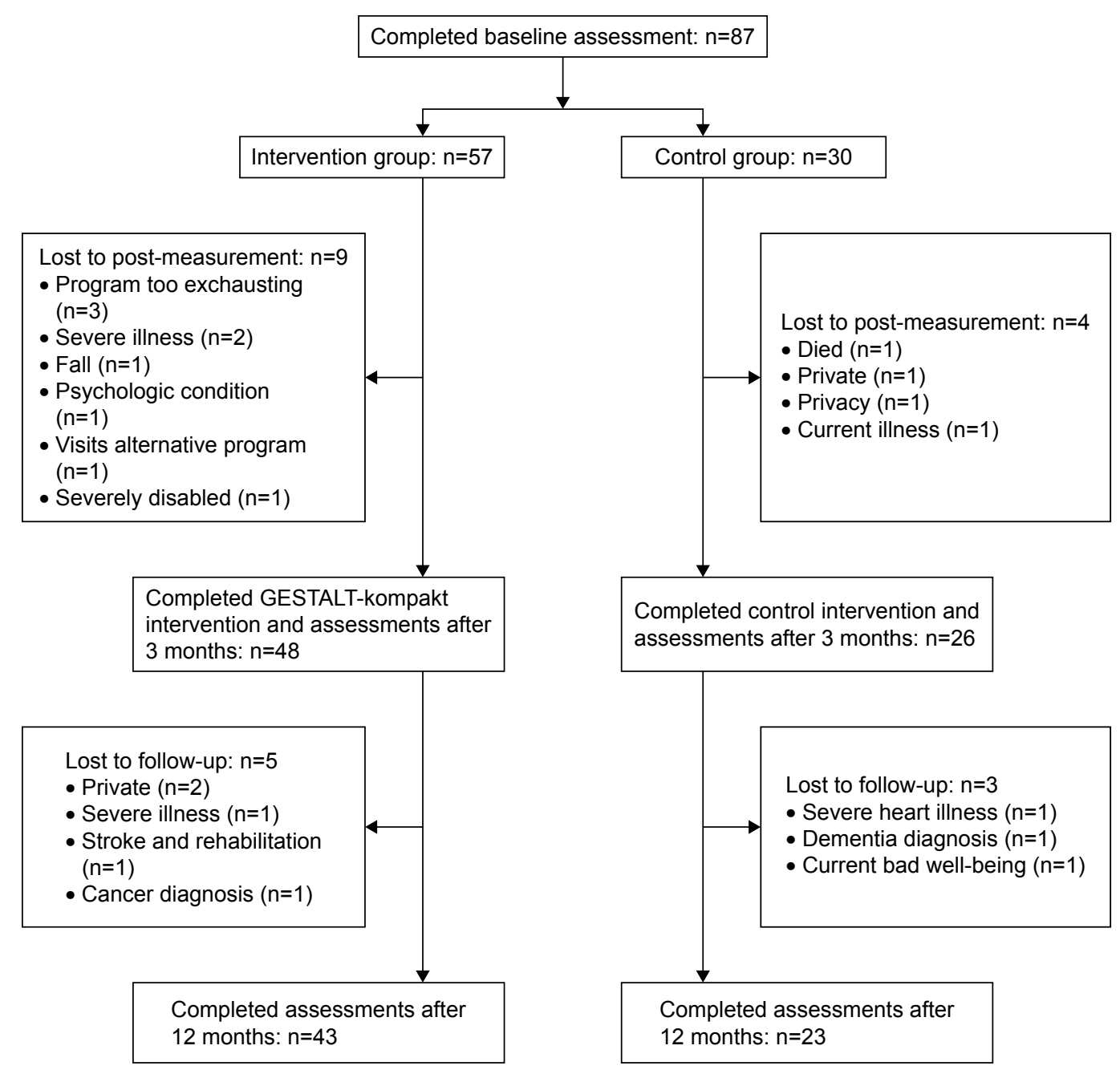

Figure I Flow diagram of the study.

Abbreviation: GESTALT, GEhen, Spielen und Tanzen Als Lebenslange Tätigkeiten [walking, playing and dancing as lifelong activities].

\section{Compliance, program satisfaction and study protocol deviations}

On average, participants of the intervention group who completed the program joined $10.2(\mathrm{SD} \pm 1.6)$ out of $12 \mathrm{PA}$ sessions (85.0\%) and 2/3 (66.6\%) excursions with their instructor. Control group participants joined $9.8(\mathrm{SD} \pm 2.3)$ out of 12 sessions (81.7\%).

On a five-point Likert scale, 32 (66.7\%) of the GESTALTkompakt participants stated that they were very satisfied, 15 participants (31.3\%) were satisfied, 1 person $(2.1 \%)$ was neutral and no one stated to be dissatisfied or very dissatisfied with the program.

Regarding the study protocol, the content of the PA program was meanwhile adapted to the higher age and severe physical limitations (eg, walking limitations) of the participants in the two assisted living facilities. Some tasks were performed while sitting instead of standing. The other three intervention groups adhered to the program.

\section{Outcomes}

Mean values and standard deviations for all points of measurement and outcomes are shown in Table 5. All time and interaction effects for the measured outcomes are shown in Table 6.

\section{Physical activity}

At 3 months, there was a significant increase in the average number of steps in the intervention group, but not in the control group. However, the interaction effect was not significant (866.4 steps, $p=0.055$ ). From $\mathrm{T} 1$ to $\mathrm{T} 2$, there was no significant interaction effect, but a significant decrease in steps was detected in the intervention group. There was no overall effect of the intervention on the PA of participants over both phases.

Looking at the assignment to the graduated step index ${ }^{39}$ (Figure 2), one can see from which category to which category the changes in mean steps have occurred. In the intervention 
Table 4 Baseline characteristics of GESTALT-kompakt and control group participants

\begin{tabular}{|c|c|c|c|}
\hline Baseline characteristics n (\%) & $\begin{array}{l}\text { Total sample } \\
\mathrm{n}=87\end{array}$ & $\begin{array}{l}\text { IG } \\
n=57\end{array}$ & $\begin{array}{l}C G \\
n=30\end{array}$ \\
\hline \multicolumn{4}{|l|}{ Nonmodifiable risk factors } \\
\hline Age (years), mean (SD) & $75.98(9.2)$ & $73.47(10.1)$ & $78.30(6.7)$ \\
\hline Gender (female) & $68(78.2)$ & $45(79.0)$ & $23(76.7)$ \\
\hline \multicolumn{4}{|l|}{ Physical activity behavior } \\
\hline Sedentary ${ }^{a}$ & $36(4 I .4)$ & $21(36.8)$ & $15(50.0)$ \\
\hline Walking aid ${ }^{\mathrm{b}}$ & $17(19.5)$ & $9(15.8)$ & $8(26.7)$ \\
\hline \multicolumn{4}{|l|}{ Cardiovascular factors } \\
\hline Overweight $t^{\mathrm{b}}$ & $4 I(47.1)$ & $28(49.1)$ & $13(43.3)$ \\
\hline High blood pressure ${ }^{\mathrm{b}}$ & $48(55.2)$ & $31(54.4)$ & $17(56.7)$ \\
\hline Heart complaints ${ }^{\mathrm{b}}$ & $25(28.7)$ & $13(22.8)$ & $12(40.0)$ \\
\hline Feeling pressure in chest while being active ${ }^{b}$ & $13(14.9)$ & $10(17.5)$ & $3(10.0)$ \\
\hline Diabetes $^{b}$ & $14(16.1)$ & $8(14.4)$ & $6(20.0)$ \\
\hline History of stroke ${ }^{b}$ & $\mathrm{I}(\mathrm{I} .2)$ & I (I.75) & $0(0)$ \\
\hline Arterial disturbed blood circulation ${ }^{\mathrm{b}}$ & $5(5.8)$ & $2(3.5)$ & $3(10.0)$ \\
\hline Venous disturbed blood circulation ${ }^{\mathrm{b}}$ & $28(32.2)$ & $20(35.1)$ & $8(26.7)$ \\
\hline \multicolumn{4}{|l|}{ Self-reported medical disorders } \\
\hline Depression $^{\mathrm{b}}$ & $7(8.1)$ & $6(10.5)$ & I (3.3) \\
\hline Mild cognitive impairment ${ }^{c}$ & $17(19.5)$ & $9(15.8)$ & $8(26.7)$ \\
\hline Dementia $^{d}$ & $3(3.5)$ & $2(3.5)$ & I (3.3) \\
\hline Carcinoma $^{\mathrm{b}}$ & $5(5.8)$ & $3(5.3)$ & $2(6.7)$ \\
\hline Pulmonary disease ${ }^{b}$ & $10(11.5)$ & $4(7.0)$ & $6(20.0)$ \\
\hline Rheumatic illnesses $^{b}$ & $8(9.2)$ & $4(7.0)$ & $4(13.3)$ \\
\hline Thrombosis, embolism ${ }^{b}$ & $3(3.5)$ & $2(3.5)$ & I (3.3) \\
\hline Epilepsyb & $\mathrm{I}(\mathrm{I} .2)$ & $0(0)$ & I (3.3) \\
\hline Thyroid disease $^{\mathrm{b}}$ & $16(18.4)$ & $10(17.5)$ & $6(20.0)$ \\
\hline Serious injury in the past ${ }^{\mathrm{b}}$ & $13(14.9)$ & $7(12.3)$ & $6(20.0)$ \\
\hline Operation in the last 6 months $^{\mathrm{b}}$ & $13(14.9)$ & $7(12.3)$ & $5(16.7)$ \\
\hline Allergies $^{\mathrm{b}}$ & $26(29.9)$ & $14(24.6)$ & $12(40.0)$ \\
\hline \multicolumn{4}{|l|}{ Social factors } \\
\hline Living alone ${ }^{\mathrm{b}}$ & $46(52.9)$ & $32(56.1)$ & 14 (46.7) \\
\hline Assisted living & $36(4 I .4)$ & $24(42.1)$ & $12(40.0)$ \\
\hline Education $^{e}$ & $32(36.8)$ & $20(35.1)$ & $12(40.0)$ \\
\hline \multicolumn{4}{|l|}{ Medical treatment } \\
\hline Current medication intake ${ }^{\mathrm{b}}$ & $74(85.1)$ & $50(87.7)$ & $24(80.0)$ \\
\hline Current medical treatment ${ }^{b}$ & $40(46.0)$ & $25(43.9)$ & 14 (46.7) \\
\hline Oxygen unit ${ }^{\mathrm{b}}$ & $2(22.7)$ & I (I.7) & I (3.3) \\
\hline
\end{tabular}

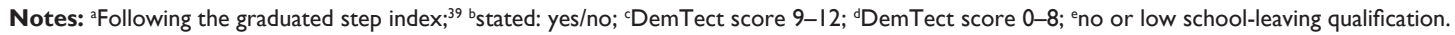

Abbreviations: CG, control group; GESTALT, GEhen, Spielen und Tanzen Als Lebenslange Tätigkeiten [walking, playing and dancing as lifelong activities]; IG, intervention group.

group, the largest shifts from T0 to T1 appeared from "low activity" to "somewhat active" or "active" and from T1 to T2, it was the other way around. In the control group, there was no such tendency.

Figure 3 shows the results of mean step counts for each prevention provider and group. Particularly striking here are, above all, the very different initial levels of PA between the groups. Participants from provider 3 had a very high initial level with an average of 8,290 steps at baseline. On the other hand, participants from provider 5 had a comparatively much lower initial level with around 2,490 steps on average. Three out of five intervention groups (providers 1, 3

Table 5 Primary and secondary outcomes by group at baseline, 3 and 12 months

\begin{tabular}{|c|c|c|c|c|c|c|}
\hline \multirow[t]{2}{*}{ Outcome } & \multicolumn{3}{|c|}{ Intervention group mean (SD) } & \multicolumn{3}{|c|}{ Control group mean (SD) } \\
\hline & Baseline & 3 months & 12 months & Baseline & 3 months & 12 months \\
\hline Steps $(n=79)$ & $5,398( \pm 2,821)$ & $6,783( \pm 2,685)$ & $6,042( \pm 2,619)$ & $4,537( \pm 2,7 \mid 9)$ & $4,868( \pm 2,085)$ & $4,929( \pm 2,545)$ \\
\hline Cognitive functions $(n=82)$ & $15.68( \pm 2.64)$ & $15.83( \pm 2.65)$ & $16.78( \pm 1.74)$ & $|4.7|( \pm 2.59)$ & $15.68( \pm 2.25)$ & $16.21( \pm 1.93)$ \\
\hline Social activity $(n=82)$ & $2.5 I( \pm I .0 I)$ & $2.68( \pm 1.13)$ & $2.93( \pm 0.83)$ & $2.74( \pm 1.08)$ & $3.20( \pm 0.89)$ & $2.86( \pm 1.22)$ \\
\hline
\end{tabular}


Table 6 Time and between-group effects at 3 and 12 months after baseline assessment

\begin{tabular}{|c|c|c|c|c|c|c|}
\hline \multirow[t]{2}{*}{ Outcome } & \multirow[t]{2}{*}{ Time } & \multirow{2}{*}{$\begin{array}{l}\text { Intervention group } \\
\text { (time effect) } \\
\text { Mean change }(95 \% \mathrm{Cl})\end{array}$} & \multirow{2}{*}{$\begin{array}{l}\text { Control group } \\
\text { (time effect) } \\
\text { Mean change }(95 \% \mathrm{Cl})\end{array}$} & \multicolumn{3}{|c|}{ Between-group difference (group $\times$ time) } \\
\hline & & & & $\begin{array}{l}\text { Difference of mean } \\
\text { changes }(95 \% \mathrm{Cl})\end{array}$ & $\begin{array}{l}\text { Effective size } \\
\text { Cohen (d) }\end{array}$ & $p$-value \\
\hline \multirow[t]{3}{*}{ Steps $(n=79)$} & T0-TI & $940.8 *(436.0,1,445.7)$ & $74.4(-653.3,802.1)$ & $866.4(-19.2,1,752.1)$ & 0.438 & 0.055 \\
\hline & $\mathrm{TI}-\mathrm{T} 2$ & $-1,018.3^{*}(-1,544.9,-491.8)$ & $-152.3(-889.1,584.6)$ & $-866.0(-1,771.7,39.6)$ & -0.428 & 0.061 \\
\hline & T0-T2 & $-77.5(-596.4,44 I .4)$ & $-77.9(-806.9,651.1)$ & $0.4(-894.4,895.2)$ & 0 & 0.999 \\
\hline Cognitive & TO-TI & $0.0229(-0.5410,0.5868)$ & $0.8849 *(0.1226,1.6472)$ & $-0.8620(-1.8102,0.0862)$ & -0.399 & 0.074 \\
\hline \multirow[t]{2}{*}{ functions $(n=82)$} & $\mathrm{TI}-\mathrm{T} 2$ & $0.8589 *(0.2662,1.4517)$ & $0.2369(-0.6|4|, \mid .0880)$ & $0.6220(-0.4152,1.6592)$ & 0.264 & 0.236 \\
\hline & T0-T2 & $0.8818 *(0.2839,1.4798)$ & I.1218* (0.2684, I.9753) & $-0.2400(-1.282 I, 0.802 I)$ & -0.101 & 0.648 \\
\hline Social activity & TO-TI & $0.1746(-0.0874,0.4366)$ & $0.4174 *(0.0498,0.785 \mathrm{I})$ & $-0.2428(-0.6943,0.2086)$ & -0.236 & 0.288 \\
\hline \multirow[t]{2}{*}{$(n=82)$} & TI-T2 & $0.2137(-0.0617,0.4891)$ & $-0.3324(-0.7300,0.0652)$ & 0.546 I* $(0.0624,1.0298)$ & 0.496 & 0.027 \\
\hline & T0-T2 & $0.3883 *(0.09 \mid 3,0.6853)$ & $0.0850(-0.3294,0.4994)$ & $0.3033(-0.2066,0.8132)$ & 0.261 & 0.240 \\
\hline
\end{tabular}

Note: *Indicates significant results in mean change.

Abbreviations: T0, baseline measurement; TI, measurement after 3 months; T2, measurement after 12 months.

and 5) showed an increase of mean steps to $\mathrm{T} 1$ and a similar decrease of mean steps to T2. The other two intervention groups (providers 2 and 4 ) also showed an increase of mean steps to T1, but then kept their PA level to T2 clearly above their initial level.

During the follow-up phase, negative life events occurred in both the groups $\left(\mathrm{n}_{\mathrm{IG}}=9[20.9 \%] ; \mathrm{n}_{\mathrm{CG}}=7[30.4 \%]\right)$ which completed the T2 assessment. GESTALT-kompakt participants reported fractures $(n=3)$, operations $(n=3)$, a slipped disc, an incisional hernia and an electric shock with a head trauma as negative events. Control group participants reported operations $(n=2)$, endoprosthesis $(n=2)$, an accident causing broken ribs, a stroke and syringomyelia.

\section{Cognitive functions}

After 3 months, significant improvements were observed for cognitive functions in the control group, but not in the intervention group. However, the interaction effect was not significant $(-0.86, p=0.074)$. From $\mathrm{T} 1$ to $\mathrm{T} 2$, there was no significant interaction effect, but a significant increase of cognitive functions in the intervention group. There was no overall effect of the intervention over both phases because both groups had significant improvements in DemTect scores.

\section{Social activity}

After 3 months, no significant interaction effect was observed compared to the control group. There were very small time

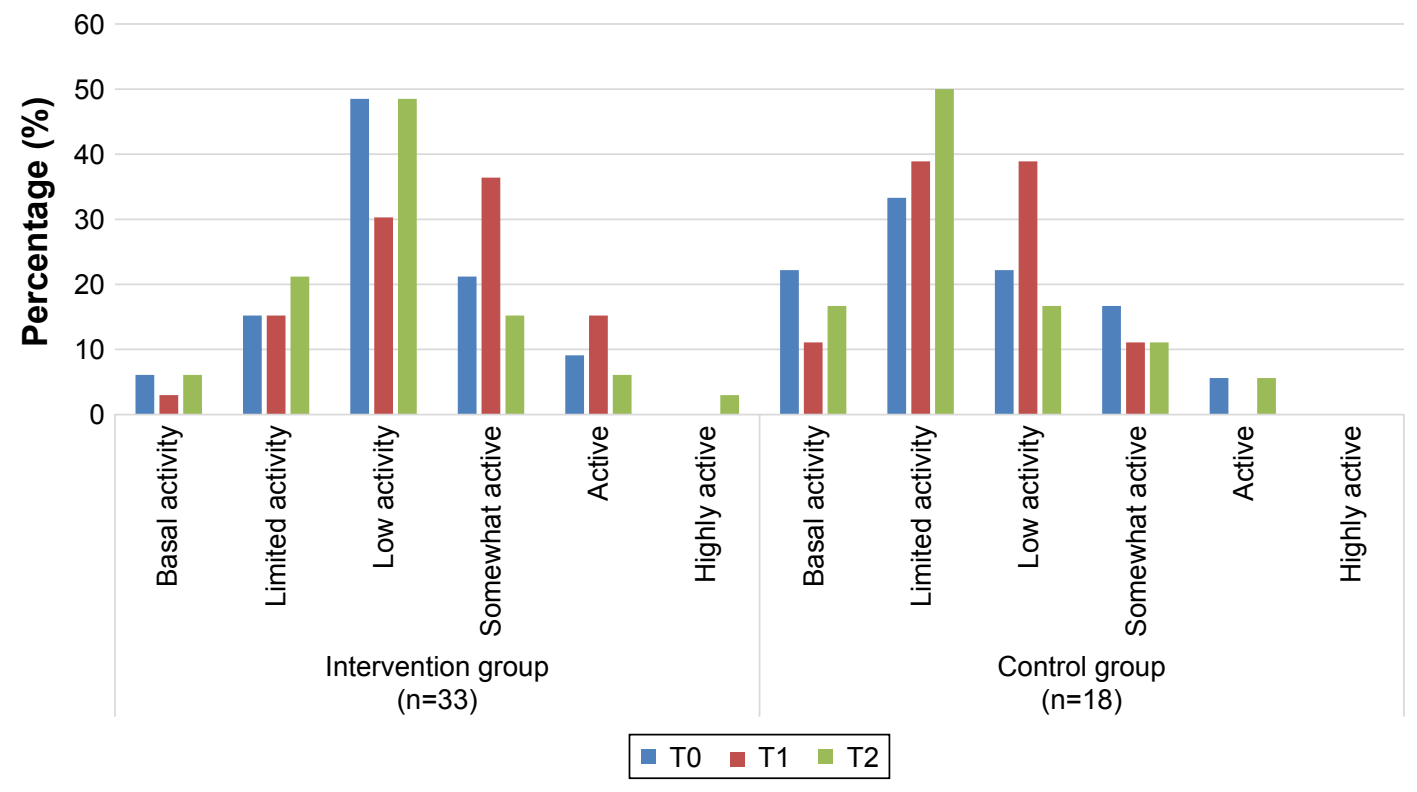

Figure 2 Assignment of mean steps to the graduated step index for both groups.

Note: This figure only includes participants who had valid results at all three points of measurement.

Abbreviations: T0, baseline measurement; TI, measurement after 3 months; T2, measurement after 12 months. 


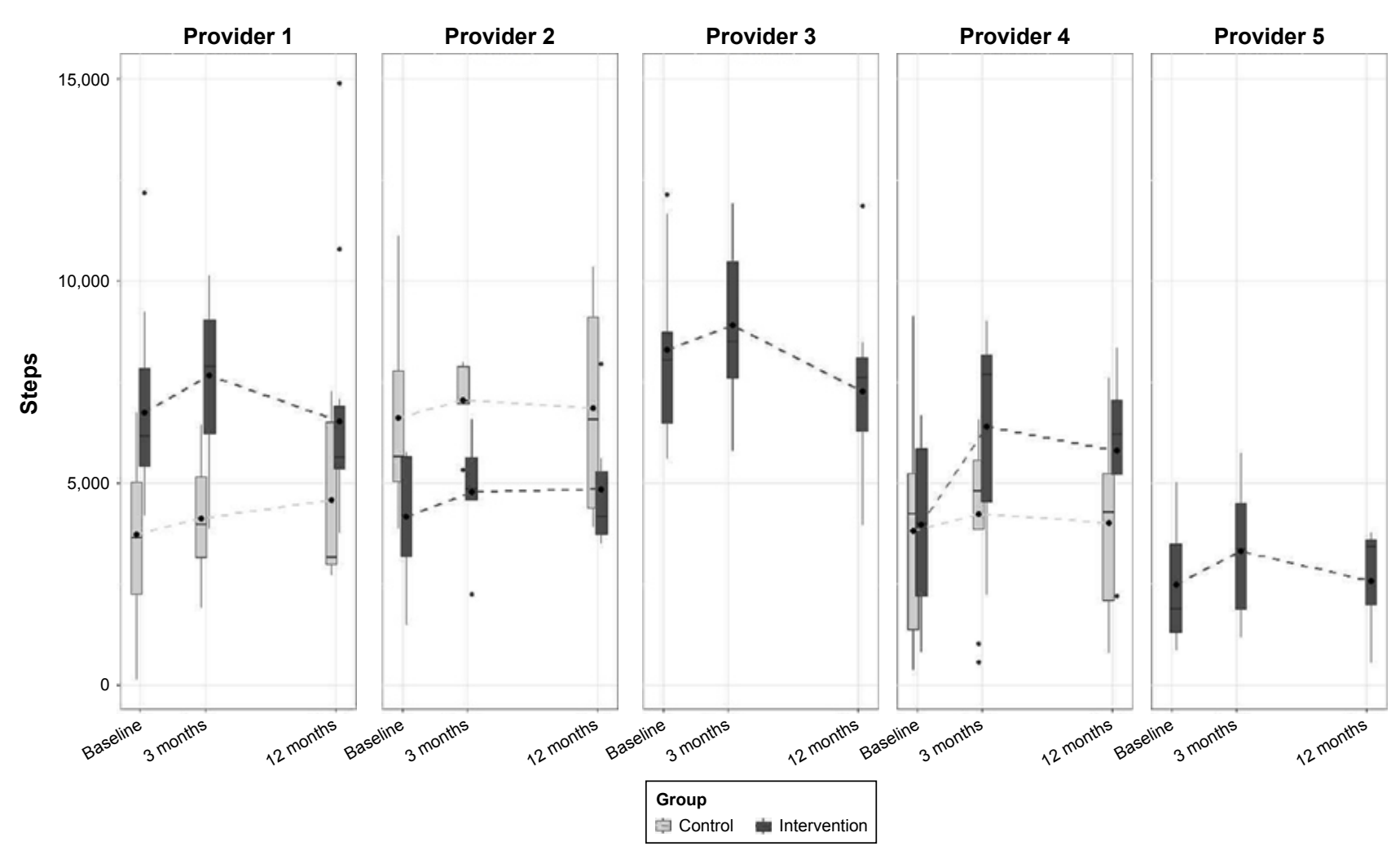

Figure 3 Boxplots of mean step counts for each provider and group.

effects after 3 months in the control group and after 12 months in the intervention group, but there was no overall intervention effect on social activities after 12 months. The baseline mean value was almost equal for the intervention and control groups. The overall mean value did slightly rise in the intervention group from $\mathrm{T} 0$ to $\mathrm{T} 1$ and again to $\mathrm{T} 2$. In the control group, there was a small increase to $\mathrm{T} 1$ and a decrease to $\mathrm{T} 2$. Looking at the three subscale mean scores, there were no prominent changes in either of them.

\section{Discussion}

Prevention of dementia is a public health concern and the translation of evidence-based prevention programs into the health care system is warranted. However, the effectiveness of such programs is seldom examined in real-world settings. There is growing evidence that highlights the promotion of PA and exercise because of its various beneficial effects on brain health and specific risk factors of dementia. This study assessed the short- and long-term effectiveness of a multimodal and multicomponent dementia prevention intervention in different real-world settings (in German health care) in older adults.

The multimodal GESTALT-kompakt intervention did not have effects on the PA of participants in the long term in comparison to an active unimodal control group, but it led to marginally significant effects after 3 months in the intervention group. No effects have been observed for cognitive functions and social activities in the short term and in the long term.

GESTALT-kompakt satisfied providers and participants, which is an important prerequisite for an effective program and for successful implementation. The interest of prevention providers and instructors in GESTALT-kompakt was high. It was successfully implemented at the sites of five prevention providers in the community and assisted living setting. Recruitment strategies through various channels reached a representative group of the Bavarian population for this age group. The 57 GESTALT-kompakt participants had a high compliance to and satisfaction with the program. The dropout rate was low, which was comparable between groups and comparable to the original GESTALT program. In GESTALT-kompakt and in GESTALT, only a few participants dropped out because of the program. Noticeably, more participants of the intervention group dropped out in the setting of assisted living. This might be due to the higher age and fragility of participants in this setting.

Many modifiable and nonmodifiable risk factors have been identified in the study population. In this study cohort, participants had multiple risk factors for dementia. The same findings were observed in a previous GESTALT study, ${ }^{31}$ 
where participants had an average of four risk factors. Regarding physical inactivity as one main risk factor, GESTALTkompakt participants improved their step counts on average by $17 \%$ from $\mathrm{T} 0$ to $\mathrm{T} 1$, which is $\sim 900$ steps/day. This increase is comparable to other pedometer-based interventions in older adults (eg, 775 steps/day) ${ }^{39} \mathrm{~A}$ conspicuous aspect was the big differences in baseline steps. Participants with basal activity at baseline $(<2,500$ steps $)$ had the fewest changes in mean steps/day in both groups. Participants with the highest baseline values to T0 (active and high active) suffered the highest losses in both groups. Most improvements were observed for participants with limited to low activity levels at $\mathrm{T} 0$ in both groups. Thus, we assume that the baseline PA level of participants might moderate the effectiveness of the study. Taking into account the intervention length, the 12-week GESTALT-kompakt program showed its effectiveness for a specific subgroup of older adults. It can be speculated that longer interventions might be a more adequate strategy to initiate and maintain PA of older adults with even lower PA levels at baseline. Considering implementation aspects, however, the shortening of the program was beneficial to better reach physically inactive persons than in GESTALT (lower entry barrier) ${ }^{37}$ and fit the needs of prevention providers (funding by health insurances). Future research might be needed to strike the right balance between the two.

Considering the determinants of PA of older adults, for example, health status and motivation, the heterogeneous subgroups might require different and more personalized approaches (eg, a person with high motivation and limited health status vs a person with low motivation and good health status). A meta-analysis supports this finding, stating that PA interventions tested among healthier older adults were more effective in improving PA behavior than in chronically ill subjects. ${ }^{47}$ The high amount of negative life events during the follow-up period should be considered for power calculations. As they occurred to a similar number of participants in both groups, they did not distort the long-term effects.

Consequently, this affects the secondary outcomes. GESTALT-kompakt did not lead to significant improvements in cognitive functions of the older adults, compared to the active control group within the study period. Both groups had high baseline values of 15.7 and 14.7 from 18.0 possible points. In both groups, there were slight increases in the mean value at all three points of measurement, whereby the control group showed slightly more increase overall. This may be explained by the lower baseline value of the control group. Participants might have become familiar with the assessment procedure.
Regarding social activity, the intervention did not lead to improvements, compared to the active control group. One reason might be that due to the new activities initiated by GESTALT-kompakt, the usual activities of participants simultaneously decreased, so that the overall quantity of social activities stayed the same. In the assisted living facility, the health status was a major barrier to taking up social activities. It is suggested that different factors at the individual, interindividual, organizational and community levels influence if and how much the social activities change.

\section{Strengths and limitations}

The strengths of our study include a manualized, multimodal, multicomponent evidence-based PA program, a high treatment integrity according to the study protocol supported by the detailed manualized procedure and training of instructors, high compliance to and satisfaction with the program, objective measurement of PA behavior, reach of physically inactive people, successful implementation in practice, as well as public and independent funding of the study. The GESTALT-kompakt study was enriched by a high diversity of settings, providers, instructors and participants. The outcomes and measures of GESTALT-kompakt were chosen in a participatory planning process together with all stakeholders to ensure relevance.

Multicomponent and multimodal interventions - such as GESTALT-kompakt - are needed for optimum effects in dementia prevention. ${ }^{48}$ Nevertheless, this involves challenges regarding study design and measures. The given financial and personnel conditions of the study allowed a controlled design with three points of measurement. To get more conclusive results and to learn exactly how the intervention influences physical, cognitive and social activity behavior of participants, a single-case experimental design with repeated measurements offers a considerable option. When participants are only measured before and after the study, the typical pattern of natural fluctuation of the variables is often unknown, making it difficult to distinguish between the natural patterns of fluctuation and a true intervention effect.

To map the complexity of dementia and its risk factors targeted by multimodal interventions, another possibility would be a statistical analysis of a composite endpoint consisting of physical, cognitive and social activities. Therefore, bigger sample sizes are needed.

Moreover, we based parts of the measures on self-report, which could be influenced by response bias. The objective measurement of physical activities by pedometer could have 
been influenced by increased motivation to be active through wearing the device at baseline. However, this counts for intervention and control groups.

The cognitive measure (DemTect) could be influenced by recall bias. To minimize this influence, two available versions of the test were used alternately. New scoring routines for people $60+$ years vs $80+$ years have been established for version A, but not for version B of the DemTect yet. Therefore, no adjustment to age was possible, even if the instrument has proven to be age dependent but not education dependent. ${ }^{49}$

An economic evaluation is warranted in future studies.

\section{Conclusion}

The GESTALT-kompakt study investigated if an evidencebased multimodal program (GESTALT) which was reduced to a 12-week version has short- and long-term effectiveness compared to the standard prevention approach in Germany in real-world settings. PA is a proximal health behavior that should be an integral part of multimodal interventions because it has the potential to address several risk factors and disease mechanisms simultaneously.

Results of GESTALT-kompakt showed a considerable time effect on the primary outcome PA at T1 in the intervention group, but not on the cognitive functions and social activities of the participants. No overall effects could be measured after 12 months. Hence, we have to assume that the 12-week intervention with its methods to increase and maintain PA levels over time was too short to cause lasting changes in lifestyle and cognition. Therefore, we recommend PA programs with longer duration ( $>6$ months) to change the behavior persistently and plea for an adaptation in German funding schemes to support this goal.

As the effectiveness of the intervention might depend on the individual initial levels of PA, cognitive functions and social activities before the beginning of the program, some participants might profit more from the multimodal approach of GESTALT-kompakt than others do. The heterogeneous subgroups within the older adults (eg, very inactive and limited health status) might require different and even more personalized approaches.

\section{Acknowledgments}

We would like to thank Andrea Wolff for her work in the GESTALT projects and many helpful suggestions and discussions. Many thanks go to Rene Streber for his proofreading of the manuscript. Many thanks go to ASTRUM IT $\mathrm{GmbH}$ for providing software to transfer step counts from the Fitbit website into a data file. We would like to thank Lee Goodwin for his linguistic revision of the manuscript. GESTALT: Bavarian State Ministry of the environment and public health/Bavarian Health and Food Safety Authority. GESTALT-kompakt: Bavarian State Ministry of public health and nursing. The funding bodies did not have any role in designing the study as well as in collecting, analyzing and interpreting the data or in writing the manuscript.

\section{Disclosure}

The authors report no conflicts of interest in this work.

\section{References}

1. World Health Organization. Dementia: A Public Health Priority. Geneva: WHO; 2012.

2. The Lancet Neurology. G8 dementia summit: a chance for united action. Lancet Neurol. 2014;13(1):1.

3. Cavallo M, Zanalda E, Johnston H, Bonansea A, Angilletta C. Cognitive training in a large group of patients affected by early-stage Alzheimer's disease can have long-lasting effects: a case-control study. Brain Impair. 2016;17(2):182-192.

4. Cavallo M, Hunter EM, van der Hiele K, Angilletta C. Computerized structured cognitive training in patients affected by early-stage Alzheimer's disease is feasible and effective: a randomized controlled study. Arch Clin Neuropsychol. 2016;31(8):868-876.

5. Suo C, Singh MF, Gates N, et al. Therapeutically relevant structural and functional mechanisms triggered by physical and cognitive exercise. Mol Psychiatry. 2016;21(11):1633-1642.

6. Wu Y-T, Fratiglioni L, Matthews FE, et al. Dementia in western Europe: epidemiological evidence and implications for policy making. Lancet Neurol. 2017;15(1):116-124.

7. Elwood P, Galante J, Pickering J, et al. Healthy lifestyles reduce the incidence of chronic diseases and dementia: evidence from the Caerphilly cohort study. PLoS One. 2013;8(12):e81877.

8. Ahlskog JE, Geda YE, Graff-Radford NR, Petersen RC. Physical exercise as a preventive or disease-modifying treatment of dementia and brain aging. Mayo Clin Proc. 2011;86(9):876-884.

9. Podewils LJ, Guallar E, Kuller LH, et al. Physical activity, APOE genotype, and dementia risk: findings from the Cardiovascular Health Cognition Study. Am J Epidemiol. 2005;161(7):639-651.

10. Deckers K, van Boxtel MPJ, Schiepers OJG, et al. Target risk factors for dementia prevention: a systematic review and Delphi consensus study on the evidence from observational studies. Int J Geriatr Psychiatry. 2015; 30(3):234-246.

11. Daviglus ML, Bell CC, Berrettini W, et al. NIH state-of-the-science conference statement: preventing alzheimer disease and cognitive decline. Ann Intern Med. 2010;27(4):1-30.

12. Norton S, Matthews FE, Barnes DE, Yaffe K, Brayne C. Potential for primary prevention of Alzheimer's disease: an analysis of populationbased data. Lancet Neurol. 2014;13(8):788-794.

13. Fiuza-Luces C, Garatachea N, Berger NA, Lucia A. Exercise is the real polypill. Physiol. 2013;28(5):330-358.

14. Barnes DE, Yaffe K. The projected effect of risk factor reduction on Alzheimer's disease prevalence. Lancet Neurol. 2011;10(9):819-828.

15. Pedersen BK, Saltin B. Evidence for prescribing exercise as therapy in chronic disease. Scand J Med Sci Sports. 2006;16(Suppl 1):3-63.

16. Warburton DE, Charlesworth S, Ivey A, Nettlefold L, Bredin SS. A systematic review of the evidence for Canada's physical activity guidelines for adults. Int J Behav Nutr Phys Act. 2010;7:39.

17. Knopman DS, Roberts R. Vascular risk factors: imaging and neuropathologic correlates. J Alzheimers Dis. 2010;20(3):699-709. 
18. Angevaren M, Aufdemkampe G, Hjj V, Aleman A, Vanhees L. Physical activity and enhanced fitness to improve cognitive function in older people without known cognitive impairment (Review). Cochrane Collab. 2008;(3):CD005381.

19. Barnes DE, Whitmer RA, Yaffe K. Physical activity and dementia: the need for prevention trials. Exerc Sport Sci Rev. 2007;35(1):24-29.

20. Larson EB, Wang L, Bowen JD, Mccormick WC, Teri L, Crane P. Exercise is associated with reduced risk for incident dementia among persons 65 years of age and older. Ann Intern Med. 2006;144(2):73-82.

21. Young J, Angevaren M, Rusted J, Tabet N. Aerobic exercise to improve cognitive function in older people without known cognitive impairment. In: Young J, editor. Cochrane Database of Systematic Reviews. Chichester: John Wiley \& Sons, Ltd.; 2015.

22. Hughes TF, Becker JT, Lee C, Chang CH, Ganguli M. Independent and combined effects of cognitive and physical activity on incident MCI. Alzheimers Dement. 2015;11(11):1377-1384.

23. Gajewski PD, Falkenstein M. Physical activity and neurocognitive functioning in aging - a condensed updated review. Eur Rev Aging Phys Act. 2016;13(1):1.

24. Hötting K, Röder B. Beneficial effects of physical exercise on neuroplasticity and cognition. Neurosci Biobehav Rev. 2013;37:2243-2257.

25. Kirk-Sanchez NJ, McGough EL. Physical exercise and cognitive performance in the elderly: current perspectives. Clin Interv Aging. 2014; (9):51-62.

26. Fratiglioni L, Paillard-Borg S, Winblad B. An active and socially integrated lifestyle in late life might protect against dementia. Lancet Neurol. 2004;3(6):343-353.

27. Kuiper JS, Zuidersma M, Oude Voshaar RC, et al. Social relationships and risk of dementia: a systematic review and meta-analysis of longitudinal cohort studies. Ageing Res Rev. 2015;22:39-57.

28. Karp A, Paillard-Borg S, Wang H-X, Silverstein M, Winblad B, Fratiglioni L. Mental, physical and social components in leisure activities equally contribute to decrease dementia risk. Dement Geriatr Cogn Disord. 2006;21(2):65-73.

29. European Commission. Special Eurobarometer - Sport and Physical Activity. Vol 334; Belgium. 2010.

30. Rütten A, Abu-Omar K, Niedermeier M, et al. GESTALT - exercise therapy intervention concept for Alzheimer disease. Bewegungstherapie und Gesundheitssport. 2009;25(6):254-261.

31. Streber A, Abu-Omar K, Wolff A, Rütten A. Preventing dementia through physical activity. Evidence-based multimodal physical activity intervention: GESTALT. Prävention und Gesundheitsförderung. 2014; (9):92-98

32. World Health Organization. Global Recommendation on Physical Activity for Health. Geneva: WHO; 2010.

33. Hamacher D, Hamacher D, Rehfeld K, Hokelmann A, Schega L. The effect of a six months dancing program on motor-cognitive dual task performance in older adults. J Aging Phys Act. 2015;23(4):647-652.

34. Glasgow RE. What does it mean to be pragmatic? Pragmatic methods, measures, and models to facilitate research translation. Heal Educ Behav. 2013;40(3):257-265.
35. Thorpe KE, Zwarenstein M, Oxman AD, et al. A pragmatic-explanatory continuum indicator summary (PRECIS): a tool to help trial designers. $J$ Clin Epidemiol. 2009;62(5):464-475.

36. Loudon K, Treweek S, Sullivan F, Donnan P, Thorpe KE, Zwarenstein M. The PRECIS-2 tool: designing trials that are fit for purpose. BMJ. 2015; 350:h2147.

37. Rütten A, Wolff A, Streber A. Interactive knowledge to action in health promotion: the GESTALT Project. Initial results of a pilot study on sustainable implementation of an evidence-based programme. Gesundheitswesen. 2016;78(6):359-366.

38. Ferguson T, Rowlands A V, Olds T, Maher C. The validity of consumerlevel, activity monitors in healthy adults worn in free-living conditions: a cross-sectional study. Int J Behav Nutr Phys Act. 2015;12:42.

39. Tudor-Locke C, Craig CL, Aoyagi Y, et al. How many steps/day are enough? For older adults and special populations. Int J Behav Nutr Phys Act. 2011;8(80):1-19.

40. Kalbe E, Kessler J, Calabrese P, et al. DemTect: a new, sensitive cognitive screening test to support the diagnosis of mild cognitive impairment and early dementia. Int J Geriatr Psychiatry. 2004;19(2):136-143.

41. Kohn N, Kalbe E, Georg H, Kessler J. Vergleich MMST und DemTect: Spezifität und Sensitivität bei primär kognitiven Störungen. Akt Neurol. 2007;34:P672.

42. Kessler J, Calabrese P, Kalbe E, Berger F. DemTect - ScreeningVerfahren zur Unterstützung der Demenzdiagnostik. Psycho. 2000; 26:343-347.

43. Castel LD, Williams KA, Bosworth HB, et al. Content validity in the PROMIS social-health domain: a qualitative analysis of focus-group data. Qual Life Res. 2008;17(5):737-749.

44. Syrjala KL, Stover AC, Yi JC, Artherholt SB, Abrams JR. Measuring social activities and social function in long-term cancer survivors who received hematopoietic stem cell transplantation. Psychooncology. 2010; 19(5):462-471.

45. Stadt Erlangen. Abteilung Statistik und Stadtforschung. Repräsentative Bürgerbefragung "Leben in Erlangen."; Erlangen 2012.

46. Bayerisches Landesamt für Gesundheit und Lebensmittelsicherheit. Gesundheitsreport Bayern.; Erlangen 2009.

47. Chase J-AD. Interventions to increase physical activity among older adults: a meta-analysis. Gerontologist. 2015;55(4):706-718.

48. Ngandu T, Lehtisalo J, Solomon A, et al. A 2 year multidomain intervention of diet, exercise, cognitive training, and vascular risk monitoring versus control to prevent cognitive decline in at-risk elderly people (FINGER): a randomised controlled trial. Lancet. 2017;385(9984): 2255-2263.

49. Kessler J, Fengler S, Kaesberg S, et al. DemTect 40- and DemTect 80+: new scoring routines for these age groups. Fortschr Neurol Psychiatr. 2014;82(11):640-645
Clinical Interventions in Aging

\section{Publish your work in this journal}

Clinical Interventions in Aging is an international, peer-reviewed journal focusing on evidence-based reports on the value or lack thereof of treatments intended to prevent or delay the onset of maladaptive correlates of aging in human beings. This journal is indexed on PubMed Central, MedLine,

\section{Dovepress}

CAS, Scopus and the Elsevier Bibliographic databases. The manuscript management system is completely online and includes a very quick and fair peer-review system, which is all easy to use. Visit http://www.dovepress. com/testimonials.php to read real quotes from published authors. 